\title{
Associated factors of sexual and gender based violence among female high school students in Debre Markos Town, North West Ethiopia: an institutionally based cross-sectional study
}

\author{
Wassachew Ashebir ( $\sim$ ashebirwase@gmail.com ) \\ Debre Markos University https://orcid.org/0000-0003-1976-9250 \\ Abiot Ayichew \\ Department of Medicine East Gojam Hospital
}

\section{Research}

Keywords: Gender based violence, Sexual violence, Female, Student, Debre Markos, Ethiopia

Posted Date: April 5th, 2021

DOI: https://doi.org/10.21203/rs.3.rs-310648/v1

License: (c) (i) This work is licensed under a Creative Commons Attribution 4.0 International License. Read Full License 


\section{Abstract}

Background: Sexual and gender based violence (SGBV) continues to be a concern of health, sexual and reproductive rights, sustainable peace and development issue that cuts across boundaries, cultural backgrounds and socio-economic groups to touch individuals of every sort around the world. SGBV remains one of the greatest inequalities of our time that takes life, violates the right they are entitled with, and seriously endangers women and girl's mental and physical wellbeing, as well as sexual and economical security. This study aimed to assess the prevalence and associated factors of sexual and gender based violence among female high school students in Debre Markos Town, North West Ethiopia:.

Methods: An institutionally based-cross-sectional study was conducted among 309 randomly selected female high school students in Debre Markos Town. Data was collected using self- administered questionnaire. Data was analyzed using multivariate logistic regression with odds ratio and $95 \%$ confidence interval to identify factors associated with sexual and gender based violence. Statistical significance was declared at $p$-value $<0.05$.

Results: The lifetime prevalence of GBV, sexual violence, and physical violence were found to be 47.0, 23.3 , and $39.5 \%$, respectively. The prevalence of sexual violence in the current academic year was $13.2 \%$. Ever drink alcohol (AOR $=0.39 ; 95 \% \mathrm{Cl}$ : 0.18-0.86), have friends using substances $(\mathrm{AOR}=0.26 ; 95 \% \mathrm{Cl}$ : $0.09-0.82)$, Grade level (AOR $=3.15 ; 95 \% \mathrm{Cl}$ : $1.32-7.48)$, witnessing parental conflict $(\mathrm{AOR}=0.29 ; 95 \% \mathrm{Cl}$ : $0.17-0.52)$, ever discuss gender related issues (AOR $=2.23 ; 95 \% \mathrm{Cl}: 1.31-3.78)$ and living condition of students (AOR $=3.53 ; 95 \% \mathrm{Cl}: 1.55-8.07)$ were significantly associated with gender-based violence.

Conclusion: The prevalence of sexual and gender-based-violence was high. This needs further intervention like awareness creation at school and community settings should be strengthened.

\section{Background}

By definition, any act of violence that results in, or is likely to result in physical, sexual, and psychological abuse regardless of the place it occurs denotes Gender based violence (GBV). Worldwide, GBV remains a hidden pandemic with the deepest expression of human rights abuse. It continues to be a concern of health, sexual and reproductive rights, sustainable peace and development issue that cuts across boundaries, cultural backgrounds and socio-economic groups to touch individuals of every sort around the world [1].

Being a good example of violence against women and girls (VAWG), gender based violence (GBV) is a typical and often invisible reflection of unequal gender relations in society. It is also a violation of human rights and an enemy of gender equality [2-4]. The cause of this violence is embedded in enriched harmful gender norms, attitudes, gender-based inequalities and discrimination. The status that girls and women have in the community together with the societal norm which supports men's superiority over women urges girls to tolerate and accept any forms of violence practice. On top of very undesirable sexual and reproductive health outcomes, such kind of violence and related pressure makes a woman to give less 
value for herself, societal image she expects, eventually lead her to feel a woman with no contribution and something to say $[3,5]$.

In 2013,1 in every 3 women had been beaten, faced forced sex or abused in different way mainly by a person they knows [6], while additional evidence in 2014 revealed that 1 in 5 women is sexually abused as a child [7]. In light of its public health importance, GBV remains one of the greatest inequalities of our time that takes life, violates the right they are entitled with, and seriously endangers women and girl's mental and physical wellbeing, as well as sexual and economical security. In this way, it denies their pursuit of enjoying fundamental freedoms for equality, humanistic respect and self-worth [8].

Through non consented and coerced sex as well as sexual assault, women's particularly adolescent girls face the risk of unwanted pregnancy and become vulnerable for sexually transmitted infections like HIV/AIDS. Furthermore, women and adolescent girls are at considerable risk of unforgotten psychological impacts including depression, intense stress, lowered self-worth, post-traumatic disorders, sleep disturbance and difficulty in concentration, loneliness, and withdrawal [9]. Subsequently, the added health and psychosocial effect of the violence would negatively impact girl's educational performance and meaningful involvement in development. This is because the harm they face mentally make women and girls no to be creative in ideas and thereby limit their potential to devote their labor in development works [10].

In a traditional society who is tolerant of and has acceptance for harmful violence practice, efforts to prevent the situation takes time [11]. Accordingly, varied forms of gender based violence events occur in different settings, situations and population segments with a considerable undetermined impact on the health of adolescent girls. Adolescent girls in SSA suffered a lot from the unplanned and non-consented sexual exposure they have made. This forced nature of sexual relation puts adolescent girls' at marked risk of sexual start at earlier age, sexual act against will, engagement in transactional sexual relations, and non-use of condoms [12,13].

In Ethiopia, gender based violence has been a growing concern for a long time. It has mostly affected women and girls making it very difficult for them to participate in developmental activities at family, school and community levels. GBV is becoming one of the most triggering issues in the face of the spread of HIV infections throughout the country on one hand and the physical, social and psychopathological impact on the other. The many aspects of girls' and women's life in Ethiopia are characterized by low status. Since their teenage years, an imposition of tiresome and tedious workload, family arranged and early marriage in the absence of informed choice leave girls and women with a little chance for making and acting on their own decisions [14].

Girls and women in the country are challenged with persistent and varied harmful traditional practices (HTPs), another dangerous abuse. Above $60 \%$ women of all ages were undergone to female genital cutting (FGC) with a significant health, social and psychological risks. For instance, nearly seventy percent of massive life-threatening bleeding after delivery in women is secondary to FGC and the same problem contributes for more than fifty percent of death among their babies. Despite the associated long 
lasting impact, unknown justifiable causes, unexamined societal reasons and higher prevalence, the practice shifts its nature, tend to be persistent and eradication seems difficult [15,16]. Another important HTP existed in such conservative hierarchical society of Ethiopia is early marriage. It affects the physical and mental health of women and in question to stay in school and future economic generation dream. The practice has made girls to be a parent at teenage years through bearing a number of children with short period of time while they are unprepared mentally, economically and how to run a family [17].

Precise estimates on the burden of VAWG are difficult to come across in Ethiopia. Yet, the existed anecdotal and fragmented pieces of information from media reports point to an alarming picture of the increase in vulnerability of young girls and women in the country. In Ethiopia, earlier studies revealed that the lifetime prevalence of violence among women was $50-60 \%$ and the most common type of violence reported was sexual violence with the primary perpetrators were intimate partners and close family members [18]. The magnitude of sexual, physical, and psychological violence reported among women at some point in their lives was $59 \%, 46 \%$ and $71 \%$ respectively [19]. Based on another study conducted in central Ethiopia, seventy four percent of female high school students reported sexual harassment and around eighty five percent of rape survivors were less than 18 years of age. Of the girls raped, twenty four percent had symptom suggestive of STI and nearly twenty percent were pregnant [20].

There are different factors at the individual, household, community and society level that significantly influence the greatest rates of sexual and gender based violence among adolescent's girls. Societal level factors such as harmful gender norms and attitudes that acknowledge male dominance, unreasonable social norms, low societal sanction against perpetrators and others like poverty, increased criminal acts and conflict situations in society are among the important risk factors [21,22]. In Ethiopia, among the many contributors of GBV are: culture, harmful traditional practices, poverty, and low level of community awareness [23-25].

Given that GBV is linked to gender-based power inequalities, violation of human rights, poverty, poor sexual and reproductive outcomes mainly spread of HIV, the best step in responding and preventing GBV is an attempt to ensure gender equality and transform discriminatory gender norms. In addition, enforcement in the area of legal and policy platforms has a role since actions to fill the existed gap in what the law says and the practice in ground. Further, timely responding for violence survivors, in a way that fulfills the rights they entitled with including personal security and access to services, like basic needs and healthcare services, is again crucial $[26,27]$. Nevertheless, in the current times even a gap in understanding and practices, and poor SGBV report mechanisms. Also, the legal enforcement system is insufficient, irregular and non-uniform coupled with deep rooted cultural acceptance and useless traditional view given for the practice were additional reinforcing factors for GBV existence and its persistency [28].

To the best of our knowledge, evidences related to school related gender based violence especially in high school settings in Ethiopia is scarce. Further, some of the factors suggested to be associated with GBV are not explicitly adjusted in different previous studies. In light of this, it is relevant to investigate and 
document the prevalence and multifaceted factors linked to gender based violence. Therefore, this study aimed to determine the prevalence and identify factors associated with gender-based violence among female students in Debre Markos, Ethiopia.

\section{Methods}

Study setting and population

An institutionally based-cross-sectional study was employed among high school female students in Debre Markos, Ethiopia. Debre Markos is the administrative capital city of East Gojam zone in Ethiopia, which is found at $299 \mathrm{KM}$ of North of Addis Ababa, the capital city of Ethiopia and $255 \mathrm{KM}$ East of Bahirdar, the capital city of Amhara region. Based on the 2007 national census reports, it has the estimated population number of 62,497. There are four high schools in the town [29]. The study was conducted between May 2018 and June 2018.

Sampling size determination and sampling procedure

A sample size of 309 female high school students was calculated using a single population proportion formula with a $95 \%$ confidence level, $5 \%$ margin of error, and prevalence of GBV/ sexual harassment among female high school students in Addis Ababa as 75.9\% (39) and by considering a non-response rate of $10 \%$. Stratified random sampling technique was used to select the study participants. First, female students were stratified by grade level as grade nine and grade ten. Proportion to population size sampling was used to allocate the students to their respective grade level. Then, systematic sampling technique was applied to select students using students' roster (name list) as a sampling frame. The total students (age > 15 years) in each grade were divided by the allocated sample size for each grade to find the interval $(\mathrm{K})$ and the $1 \mathrm{st}$ female student in each class was selected randomly using the lottery method

\section{Data collection instruments}

Data were collected using structured, pre-tested and self-administrated questionnaire which was adapted from previous published studies [30-32]. Four well trained grade twelve completed students who know the local language and culture were participated in the data collection activity. They helped in seating students in the classrooms designated for completing the survey and provided explanation on the study procedures and tools. They were also ensured complete privacy during completing questionnaire. The questionaries' was developed in the English language and then translated to Amharic language and back to the English language to ensure convenient information was obtained. A pre-test study before the actual data collection was done at Dibiza high school students and some modification in the questionnaire was made based on the feedback taken from the pretest.

\section{Data processing and analyses}

Data were double entered and cleaned in EPI data software version 3.1 to cross check the data for completeness before analysis. The entered data were exported and analyzed with SPSS version 22 . 
Descriptive statistics, tables, graphs, means, and frequency distribution was used to present the information. Bivariate and multivariate logistic regression with odds ratio along with the $95 \%$ confidence interval were used to ascertain the association between associated factors and the dependent variable. Pvalue $<0.05$ was considered for statistical significant.

\section{Results}

Socio-demographic characteristics of high school female students

A total of 296 out of 309 students were participated in the study giving a response rate of $95.8 \%$. The mean age (+SD) of the study participants was $16.89 \pm 1.4$ years. Of 296 students included in the study, Most (92.2\%) were Orthodox religion followers. Among the respondents; 196 (66.2\%) were grown in an urban setting, 248(83.8\%) were living with their parents, $61.1 \%$ had tight family control and $98(33.1 \%)$ had a pocket money (Table 1 ).

Table 1Socio demographic characteristics of female high school students in Debre Markos town, Ethiopia, 2018 


\begin{tabular}{|c|c|c|c|}
\hline Variables & Category & Number & Percentage (\%) \\
\hline \multirow[t]{3}{*}{ Age } & $10-14$ & 12 & 4.1 \\
\hline & $15-19$ & 279 & 94.2 \\
\hline & $20-24$ & 5 & 1.7 \\
\hline \multirow[t]{4}{*}{ Religion } & Orthodox & 273 & 92.2 \\
\hline & Protestant & 12 & 4.1 \\
\hline & Muslim & 8 & 2.7 \\
\hline & Others & 3 & 1.0 \\
\hline \multirow[t]{5}{*}{ Living condition } & With family & 248 & 83.8 \\
\hline & With female friend & 28 & 9.5 \\
\hline & Alone & 11 & 3.7 \\
\hline & With male friend & 5 & 1.6 \\
\hline & With relative & 4 & 1.4 \\
\hline \multirow[t]{2}{*}{ Pocket money } & Yes & 98 & 33.1 \\
\hline & No & 198 & 66.9 \\
\hline \multirow[t]{3}{*}{ Academic performance } & Good and above & 117 & 39.5 \\
\hline & Average & 157 & 53.0 \\
\hline & Poor & 22 & 7.4 \\
\hline \multirow[t]{3}{*}{ Perceived family income } & Satisfactory & 194 & 65.5 \\
\hline & Average & 74 & 25 \\
\hline & Poor & 28 & 9.5 \\
\hline \multirow[t]{2}{*}{ Residence } & Urban & 196 & 66.2 \\
\hline & Rural & 100 & 33.8 \\
\hline \multirow[t]{4}{*}{ Grade level } & $9^{\text {th }}$ & 95 & 32.1 \\
\hline & $10^{\text {th }}$ & 89 & 30.1 \\
\hline & $11^{\text {th }}$ & 64 & 21.6 \\
\hline & $12^{\text {th }}$ & 48 & 16.2 \\
\hline
\end{tabular}

Substance abuse and related behaviors 
The lifetime history of chewing chat, smoking cigarette/tobacco, and drinking alcohol was reported by $45.45 \%, 4.5 \%, 13.9 \%$ of the respondents respectively and $22(7.4 \%)$ respondents reported that they have a close friend who used substances.

\section{Sexual experiences}

Of the total 296 students, 11 (3.7\%) had started sexual intercourse and 8 (72.2\%) reported that they practiced sexual intercourse without their will. The mean age (+SD) for having the first sexual intercourse were found to be $16.4 \pm 2.1$ years and above $90 \%$ of respondents had one sexual partner. About 66 $(22.3 \%)$ of respondents reported that they have witnessed violence as a child. More than half $(50.3 \%)$ of respondents said that there is no free discussion with their family members on reproductive health and other gender related issues.

The prevalence of GBV

The prevalence of life time Gender based violence (physical or/and sexual violence) and during the current academic year was $139(47 \%)$ and $70(23.6 \%)$ respectively.

Physical violence

The lifetime prevalence of physical violence was found to be 117(39.5\%). The prevalence of physical violence before joining high school, since joining high school and during the current academic year were 96 (32.4\%), 57(19.3\%) and 39 (13.2\%) respectively. According to this study, the offenders of physical violence were family members /other relatives $50(42.7 \%)$, students $32(27.4 \%)$, teachers $11(9.4 \%)$, husbands/boyfriends/ partner $3(2.6 \%)$ and strange $21(17.9 \%)$. Complications of physical violence reported were disgusting people 37(31.6\%), temporary physical injury 16(13.7), poor school achievement 13(11.1\%), school failure $1(0.9 \%)$ and 50(42.7\%) reported as there in no influence (Table 2).

Table 2 Distribution of types of physical violence among female high school students in Debre Markos, Ethiopia, 2018 


\begin{tabular}{|c|c|c|c|c|}
\hline Variables & Category & $\begin{array}{l}\text { Before joining } \\
\text { high school }\end{array}$ & $\begin{array}{l}\text { Since joining } \\
\text { high school }\end{array}$ & $\begin{array}{l}\text { During } \\
\text { this } \\
\text { academic } \\
\text { year }\end{array}$ \\
\hline \multirow{2}{*}{$\begin{array}{l}\text { Ever slapped /something thrown at } \\
\text { you }\end{array}$} & Yes & $66(22.3)$ & $31(10.5)$ & $17(5.7)$ \\
\hline & No & $230(77.7)$ & 265(89.5) & $279(94.3)$ \\
\hline \multirow[t]{2}{*}{ Ever pushed /shoved } & Yes & $56(18.9)$ & $34(11.5)$ & $20(6.8)$ \\
\hline & No & $240(81.1)$ & $262(88.5)$ & 276(93.2) \\
\hline \multirow[t]{2}{*}{ Ever beaten with fist /something/ } & Yes & $22(7.4)$ & $10(3.4)$ & $5(1.7)$ \\
\hline & No & 274(92.6) & 286(96.6) & 291(98.3) \\
\hline \multirow[t]{2}{*}{ Ever choked /burnt } & Yes & $22(7.4)$ & $15(5.1)$ & $12(4.1)$ \\
\hline & No & 274(92.6) & 281(94.9) & $284(95.9)$ \\
\hline \multirow{2}{*}{$\begin{array}{l}\text { Ever threatened verbally or with } \\
\text { gun/knife }\end{array}$} & Yes & $9(3.0)$ & $10(3.4)$ & $6(2.0)$ \\
\hline & No & $287(97.0)$ & 286(96.6) & 290(98.0) \\
\hline \multirow[t]{2}{*}{ Life time physical violence } & Yes & $117(39.5)$ & & \\
\hline & No & $179(60.5)$ & & \\
\hline \multirow{2}{*}{$\begin{array}{l}\text { Any type of physical violence before } \\
\text { joining high school }\end{array}$} & Yes & $96(32.4 \%)$ & & \\
\hline & No & $200(67.6 \%)$ & & \\
\hline \multirow{2}{*}{$\begin{array}{l}\text { Any type of physical violence since } \\
\text { joining high school }\end{array}$} & Yes & $57(19.3 \%)$ & & \\
\hline & No & $239(80.7 \%)$ & & \\
\hline \multirow{2}{*}{$\begin{array}{l}\text { Any type of physical violence this } \\
\text { year }\end{array}$} & Yes & $39(13.2 \%)$ & & \\
\hline & No & $257(86.8 \%)$ & & \\
\hline
\end{tabular}

Sexual violence

The lifetime prevalence of sexual violence among female students was found to be $23.3 \%$, while forced sexual violence before joining high school, since joining high school and the current academic year was reported $6(2 \%), 12(4.1 \%)$ and $9(3 \%)$ respectively. Similarly, $9(3 \%), 7(2.4 \%)$ and $6(2 \%)$ of respondents had faced unwelcomed touch before joining high school, since joining high school and the current academic year. Prevalence of sexual violence in the current academic year was $13.2 \%$.

However, in case of perpetrators of sexual violence, the students takes the lead 29(46\%) followed by unknown person $13(20.5 \%)$. There was lots of reported health, psychological and other complications associated with sexual violence. Complications like: injury around the genitalia 20(31.7\%), swelling 
around the genitalia $19(30.2 \%)$, abortion and pregnancy $10(15.9 \%)$, unusual vaginal discharge $8(12.7 \%)$ and no physical influence $6(9.5 \%)$ while common psychological consequences experienced due to forced sex were anxiety 17 (26.9\%), depression 15 (23.8\%), fear 14(22.2\%), self-blame 6(9.5\%), hopeless $3(4.8 \%)$, suicidal ideation $3(4.8 \%)$, suicidal attempt $1(1.6 \%)$ and no psychological influence 4(6.3\%). Similarly common social consequences due to forced sex also include poor academic achievement $20(31.7 \%)$, rejection from friends $14(22.2 \%)$, rejection from family $5(7.9 \%)$, sexual dependence 2(3.2\%), Alcohol dependence 1(1.6\%) and no social influence 21(33.3\%).

Factors related to sexual and gender-based violence

In the multivariable analysis, ever drink alcohol (AOR $=0.39 ; 95 \% \mathrm{Cl}: 0.18-0.86)$, have friends using substances (AOR $=0.26 ; 95 \% \mathrm{Cl}: 0.09-0.82)$, Grade level (AOR $=3.15 ; 95 \% \mathrm{Cl}: 1.32-7.48)$, witnessing parental conflict $(A O R=0.29 ; 95 \% \mathrm{Cl}: 0.17-0.52)$, ever discuss gender related issues $(A O R=2.23 ; 95 \% \mathrm{Cl}$ : $1.31-3.78)$ and living condition of students $(A O R=3.53 ; 95 \% \mathrm{Cl}$ : $1.55-8.07)$ were significantly associated with gender-based violence (Table 3 ).

Table 3 Factors associated with sexual and GBV among female high school students in Debre Markos , Ethiopia, 2018 


\begin{tabular}{|c|c|c|c|c|c|}
\hline \multirow[t]{2}{*}{ Variables } & \multirow[t]{2}{*}{ Categories } & \multicolumn{2}{|c|}{$\begin{array}{l}\text { Life time } \\
\text { GBV }\end{array}$} & \multirow[t]{2}{*}{ COR 95\%Cl } & \multirow[t]{2}{*}{ AOR 95\%Cl } \\
\hline & & Yes & No & & \\
\hline \multirow[t]{2}{*}{ Ever drink alcohol } & Yes & 28 & 13 & 1 & 1 \\
\hline & No & 111 & 144 & $\begin{array}{l}0.36(0.18- \\
0.72)\end{array}$ & $\begin{array}{l}0.39(0.18- \\
0.86)\end{array}$ \\
\hline \multirow{2}{*}{$\begin{array}{l}\text { Have friends using } \\
\text { substances }\end{array}$} & Yes & 17 & 5 & 1 & \\
\hline & No & 122 & 152 & $\begin{array}{l}0.36(0.78- \\
0.72)\end{array}$ & $\begin{array}{l}0.26(0.09- \\
0.82)\end{array}$ \\
\hline \multirow[t]{4}{*}{ Grade level } & $9^{\text {th }}$ & 48 & 47 & 1 & 1 \\
\hline & $10^{\text {th }}$ & 43 & 46 & $\begin{array}{l}1.26(0.63- \\
2.53)\end{array}$ & $\begin{array}{l}2.33(1.04- \\
5.19)\end{array}$ \\
\hline & $11^{\text {th }}$ & 21 & 43 & $\begin{array}{l}1.38(0.68- \\
2.79)\end{array}$ & $\begin{array}{l}1.49(0.69- \\
3.26)\end{array}$ \\
\hline & $12^{\text {th }}$ & 27 & 21 & $\begin{array}{l}2.63(1.22- \\
5.70)\end{array}$ & $\begin{array}{l}3.15(1.32- \\
7.48)\end{array}$ \\
\hline \multirow{2}{*}{$\begin{array}{l}\text { Live close enough to } \\
\text { families }\end{array}$} & Yes & 107 & 146 & 1 & 1 \\
\hline & No & 32 & 11 & $\begin{array}{l}3.97(1.92- \\
8.23)\end{array}$ & $\begin{array}{l}3.53(1.55- \\
8.07)\end{array}$ \\
\hline \multirow{2}{*}{$\begin{array}{l}\text { Ever discus GBV \& RH issues with } \\
\text { family }\end{array}$} & Yes & 45 & 91 & 1 & 1 \\
\hline & No & 94 & 66 & $\begin{array}{l}0.35(1.21- \\
3.72)\end{array}$ & $\begin{array}{l}2.23(1.31- \\
3.78)\end{array}$ \\
\hline \multirow{2}{*}{$\begin{array}{l}\text { Witnessing parental } \\
\text { conflict as a child }\end{array}$} & Yes & 68 & 31 & 1 & 1 \\
\hline & No & 71 & 126 & $\begin{array}{l}0.26(0.15- \\
0.43)\end{array}$ & $\begin{array}{l}0.29(0.17- \\
0.52)\end{array}$ \\
\hline
\end{tabular}

\section{Discussion}

The study assessed prevalence of gender based violence and associated factors among female high school students in Debre Markos town. The life time and current prevalence of gender based violence among high school female students in the current study area was found to be $47 \%$ and $23.6 \%$ respectively. The prevalence of life time physical and sexual violence was $39.5 \%$ and $23.3 \%$. In addition, the prevalence of current year physical and sexual violence was found to be $13.2 \%$ and $17.6 \%$. Other similar study conducted among female high school students in Butajira, Southern Ethiopia showed that the prevalence of life time physical and sexual violence was 15.5 and 35.5, and that of current year physical and sexual violence was found to be $35.2 \%$ and $19.1 \%$ [33]. Possible reason for such differences 
among the two studies could be due to the difference in socio demographic characteristics and the difference in time.

The current year prevalence of completed rape was $3 \%$ and that of attempted was $4 \%$ while the case of sexual harassment being $9.8 \%$. In the above study completed and attempted rape were $2.5 \%$ and $10.7 \%$ respectively with sexual harassment of $15.4 \%$. The findings in both studies were comparable. Similarly a study on prevalence and factors related to sexual violence among high school students of Addis Ababa and Western Shewa, completed and attempted rape was $5.1 \%$ and $10.1 \%$ [20]. These findings were also comparable with the current study findings.

Major complications of physical violence were disgusting people $31.6 \%$, temporary physical injury $13.7 \%$, poor school achievement $11.1 \%$, and school failure $0.9 \%$. Family members $36.8 \%$ and students $27.4 \%$ were the common sources of physical violence among the respondents. Similar study among female students of Menkorer high school in Debre Markos town, Northwest Ethiopia showed common consequences of physical violence among participants were disgusting people, 40\%, poor school achievement $29.3 \%$, and school failure $14.6 \%$. The most common individuals who committed physical violence were family members, $47.6 \%$, followed by students $34.5 \%$ [31]. Findings of the current study were lower than the previous finding. This difference could be due to the differences in educational level and number of high schools included in the study. The current study includes all high schools in the town with educational levels of 9 up to 12, whereas the previous study includes only one high school with educational levels of 9 to 10 .

Gender based violence (physical and/or sexual violence) was analyzed for possible association with the independent variables. Accordingly; drinking alcohol, having peers who used substances, living condition, educational status, witnessing marital conflict as a child and ever discus gender related and other reproductive health issues with family members were found to have an association with GBV. Findings like drinking alcohol, having peers who used substances and educational status were supported by study findings from WHO world report on violence and health [3]. From factors associated with GBV: students who never drinking alcohol, did not had peers using substances and never witnessed marital conflict had a decreased risk by $39 \%, 26 \%$ and $29 \%$ respectively. Possible reason for this could be due violent behavior of students on the category of those who had peers using substances, impaired judgment of students who drink alcohol and behavioral impact of being witnessing marital conflict while child.

On the other hand students who never discuss gender related issues and not live close enough to their families were more likely to face GBV 2.23 times and 3.53 times respectively. The reason could be lack of awareness on consequences of gender related health issues and lack of family protection. Regarding educational status, students with 12th grade had 3.15 times more likely hood of GBV compared to those with 9th grade. Similarly those students in the educational level of 10th and 11th had 2.33 times and 1.49 times more likely hood of GBV. The possible reason could be due to being matured in age and sexuality makes the students to experience violent behavior. 
The current findings of alcohol drinking, having peers who ever used substances, living far from parents/guardian and ever discuss gender related and other reproductive health issues were documented in other similar study findings in Ethiopia [20]. On other similar study conducted five years back in the same area, never drinking alcohol had a decreased risk by $38 \%$ and witnessing violence as a child increase the risk 2.07 times [33]. In the current study never drinking alcohol decrease the likely hood

of experiencing GBV by $45 \%$ and never witness violence as a child by $34 \%$ in this academic year. Possible reason for such a discrepancy could be due to time difference and subsequent intervention measures that could be taken throughout this time gap.

\section{Conclusion}

According to this study finding, Gender based violence is still a problem of female high school students. But magnitude of the problem is decreasing compared to the previous similar studies.

The life time and current prevalence of gender based violence was found to be $47 \%$ and $23.6 \%$ respectively. Similarly the prevalence of life time physical and sexual violence was $39.5 \%$ and $23.3 \%$. In addition, the prevalence of current year physical and sexual violence was found to be $13.2 \%$ and $17.6 \%$. Major factors associated with Gender based violence in the study were ever drinking alcohol, having peers who used substances and educational level of students. The common consequences of physical violence were disgusting people, temporary physical injury poor school achievement and school failure.

Students have also reported several physical, psychological and social consequences of sexual violence and majority (92\%) of the respondents did not share to somebody ales even when faced completed rape. Awareness creation on Gender related issues and risk sexual behavior at school and community levels should be done for both students and parents. School teachers, parents and other stake holders in the legal system should identify and take corrective measures up on students who use substances. The importance of adolescent - parent communication on Gender related and other reproductive health issues should be advocated further on public medias. Further studies supplemented with focus group discussion recommended for better understanding of factors associated with GBV.

\section{Abbreviations}

GBV: Gender-based violence; HIV: Human immune virus; RH: Reproductive health

\section{Declarations}

Competing interests

The authors declare that they have no competing interests

Availability of data and materials 
Data will be available upon request of the corresponding authors

Consent for publication

Not applicable

Ethical approval and consent to participate

Ethical clearance was obtained from the Ethical Review Committee of College of Health Science, Debre Markos University. After the objective of the study was explained, verbal consent was obtained from the school administration and both verbal and written consent was obtained from each participant. Moreover, privacy and confidentiality of information was strictly guaranteed by all data collectors and investigators. For students whose age was $<18$ years, a written informed consent was obtained from their parents and/or guardians and an assent was obtained from each students.

Funding

No fund is obtained for this study

Authors' Contribution

All authors, Wassachew Ashebir and Abiot Ayichew conceptualized the research question, monitored and managed fieldwork, analyzed and interpreted the findings, and written the paper.

Acknowledgment

Debre Markos University provided opportunity and other supports for this research project. The authors are grateful to the female high school adolescents who sacrificed their time. The authors also thank the school principals and administrative bodies of the district for their necessary support and the data collectors for their responsible data collection.

\section{References}

1. USAID, Strengthening Regional work on Gender Based Violence: A meeting of activists, practitioners and researchers from the Horn, East and Southern Africa, Kampala, Uganda Nov 8-9, 2006

2. WHO. Women's Health and Domestic Violence against Women. Study Team, Prevalence of Intimate Partner Violence: findings from the WHO multi-country study on women's health and domestic violence. Lancet. 2006;368:1260-9.

3. WHO multi-country study on women's health and domestic violence against women: summary report of initial results on prevalence, health outcomes and women's responses. 2005.

4. USAID. The effects of School-Related Gender-Based Violence on academic performance evidence from Botswana, Ghana \& South Africa. 2016. 
5. World Health Organization, The forms and contexts of violence, World report on violence and health 2002: 10-40.

6. World Health Organization (2013).Global and regional estimates of violence against women: prevalence and health effects of intimate partner violence and non-partner sexual violence, Geneva, Switzerland

7. UNFPA. (2014). Baseline survey on the prevention and management of gender based violence in Ethiopia, Addis Ababa, Ethiopia

8. WHO. Putting women first: Ethical and safety recommendation for research on domestic violence against women, Geneva Switzerland, 2001

9. UN (2006). In-depth study on all forms of violence against women, Report of the Secretary-General, New York

10. Bates, L. M., Schuler, S. R., Islam, F., \& Islam, K. (2004). Socioeconomic factors and processes associated with domestic violence in rural Bangladesh. International Family Planning Perspectives, 30(4), 190-9. doi:10.1363/ifpp.30.139.04

11. Krug EG, Mercy JA, Dahlberg LL, Zwi AB. The world report on violence and health. Lancet 2002; 360(9339): 1083-8. [http://dx.doi.org/10.1016/S0140-6736(02)11133-0] [PMID: 12384003]

12. Moore AM, Awusabo-Asare K, Madise N, John-Langba J, Kumi-Kyereme A. Coerced first sex among adolescent girls in sub-Saharan Africa: Prevalence and context. Afr J Reprod Health 2007; 11(3): 6282. [http://dx.doi.org/10.2307/25549732] [PMID: 18458747]

13. Ellsberg M. Violence against women and the Millennium Development Goals: facilitating women's access to support. Int J Gynaecol Obstet 2006; 94(3): 325-32.

[http://dx.doi.org/10.1016/j.ijgo.2006.04.021] [PMID: 16842792]

14. UNFPA, State of the World Population, 2005.

15. Pathfinder International. Causes and Consequences of Early Marriage in the Amhara Region of Ethiopia, 2006, p. 20.

16. Ethiopian Demographic and Health Survey, 2005. CSA, Ethiopia.

17. Population Reference Bureau, (PRB) 2006 World Population Data Sheet (http://www.prb.org/datafind/).

18. Gossaye Y., Deyessa N., Berhane Y., Ellsberg M., Emmelin M., Ashenafi M., Alem A., Negash A., Kebede D., Kullgren G., Hogberg U., 2003. Women $\llbracket$ s Health and Life Events Study in Rural Ethiopia. Ethiopian Journal of Health Development; 17

19. Garcia-Moreno, C., Jansen, H. A., Ellsberg, M., Heise, L., \& Watts, C. H. (2006). Prevalence of intimate partner violence: Findings from the WHO multi country study on women's health and domestic violence. Geneva: World Health Organization, Department of Gender, Women and Health.

20. Mulugeta E, Kassaye M, Berhane Y. Prevalence and outcomes of sexual violence among high school students. Ethiop Med J. 1998;36(3):167-74.

21. UNICEF. Domestic violence Against women and girls. Innocenti Digest. Italy, June 2000. 
22. Population Council. Sexual and gender based violence in Africa. Literature review. Feb 2008.

23. Save the Children Denmark, Ministry of Education and Ministry of Women Affairs. 2008. A Study on Violence against Girls in Primary Schools and Its Impacts on Girls' Education in Ethiopia.

Development Assistance Group (DAG), SCD, MoE \& MoWA, Addis Ababa (http://www.ungei.org/resources/files/Study_on_Violence_Against_Schoolgfils_final.pdf)

24. UNICEF \& MoLSA (2005). Violence against children in Ethiopia. AA: MoLSA

25. Ministry of Women, Children and Youth Affairs (MoWCYA). 2013. The National Strategy and Action Plan on Harmful Traditional Practices against Women and Children in Ethiopia. FDRE MoWCYA, Addis Ababa

26. IGWG of USAID. Addressing gender-based violence through USAID health programs. A guide for health sector program officers. Washington, 2006.

27. UN Women (2011). UN Women Report 2010-2011, New York

28. Federal Democratic Republic of Ethiopia ( $\mathrm{MOH})$. National Guideline for the Management of Survivors of Sexual Assault in Ethiopia. Nov 2009.

29. Debre Markos history and demographic. [Internet]. [Cited 2018 January 19]. Available from: www.en.wikipedia.org/wiki/Debre_Marqos

30. Fitaw Y, Haddis K, Million F, et al. Gender Based Violence among High School Students in North West Ethiopia. Ethiopian Medical Journal: January 2005; 43(4): 215-221.

31. Getachew Mullu et al. Prevalence of Gender Based Violence and Associated Factors among Female Students of Menkorer High School in Debre Markos Town, Northwest Ethiopia: Science Journal of Public Health 2015; 3(1)

32. Gelane $L$ and Lukman $Y$. A cross sectional study on prevalence of gender based violence in three high schools, Addis Ababa, Ethiopia: Ethiopian Journal of Reproductive Health, 2008:2(1).

33. Miruts Goshu, Yemane Berhane, Negussie Deyessa: Prevalence and Factors Related to Sexual and Physical Violence among Female High School and Technical School Students of Butajira, SNNPR, Ethiopia (Unpublished MPH Thesis) 2006. 